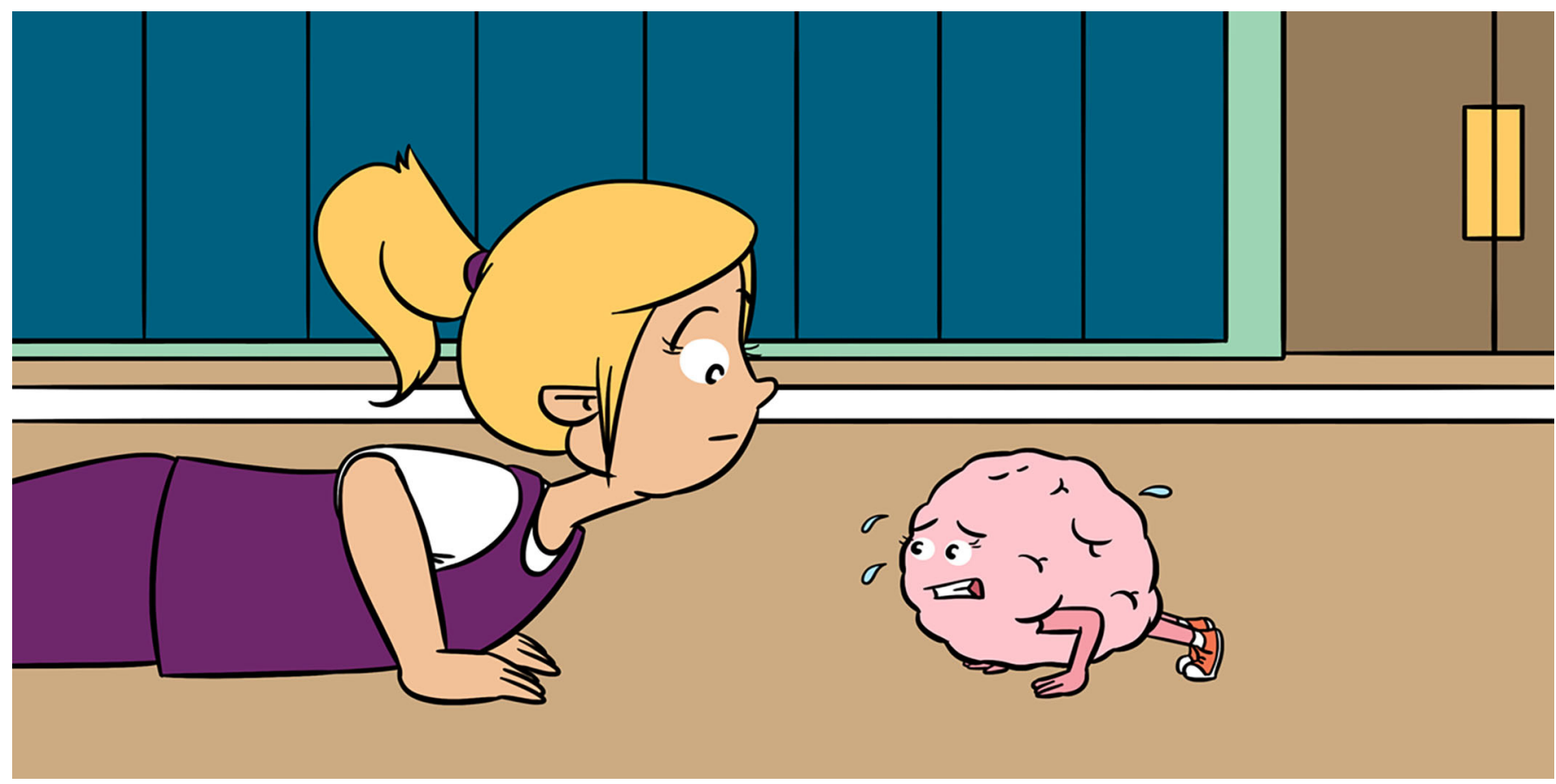

\title{
ARE YOUR MUSCLES OR YOUR BRAIN MAKING YOU FEEL TIRED AFTER EXERCISE?
}

Derek Zhang ${ }^{1}$, Juana Li $^{1}$, Ryan Miller ${ }^{1}$, Marina Batraka ${ }^{1}$, Sophie Marie Anne Effing ${ }^{1}$, Fahmida Hossain ${ }^{1}$, Anne-Catherine Bernard ${ }^{2,3}$, Mathieu Marillier ${ }^{2,3}$ and Nicolle J. Domnik ${ }^{1,4 *}$

${ }^{1}$ Department of Biomedical and Molecular Sciences, Queen's University, Kingston, ON, Canada

2 Department of Medicine, Queen's University, Kingston, ON, Canada

${ }^{3}$ HP2 Laboratory, INSERM U1042, Grenoble Alpes University, Grenoble, France

${ }^{4}$ Department of Physiology and Pharmacology, Schulich School of Medicine and Dentistry, Western University, London, ON, Canada

YOUNG REVIEWER:

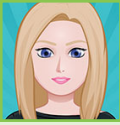

MORGAN

AGE: 13
Did you know your muscles can feel exhausted without actually being exhausted? It turns out that your brain is just as important as your muscles when it comes to fatigue, or physical tiredness. You can experience "peripheral" fatigue, which is fatigue originating from the muscles, or you can experience central fatigue, which originates from the brain and central nervous system. By studying both the brain and the muscles, scientists can examine which is causing your fatigue. But how? Do we need to perform brain surgery to get answers? Luckily, special techniques involving stimulation of the nerves and muscles can be used instead! In this article, we illustrate how scientists determine if the tiredness you feel after exercising is caused by central or peripheral fatigue or maybe both. We will also explore the differences between the two. 
Figure 1

How the brain controls the muscles. First, the brain produces the chemical-electrical signal (yellow lightning bolts). Then the signal is sent from the brain to the spinal cord (a cross-section through the spinal cord is shown). Finally, neurons relay the signal to the target muscle through their long axons. When the signal arrives in the muscle, it causes the muscle to contract.

\section{NEURON}

A cell type that makes up much of our brain and specializes in communicating information about our bodies to our brain or sending information from our brain to different parts of our bodies.

AXON

The long branch of a neuron that carries a signal.

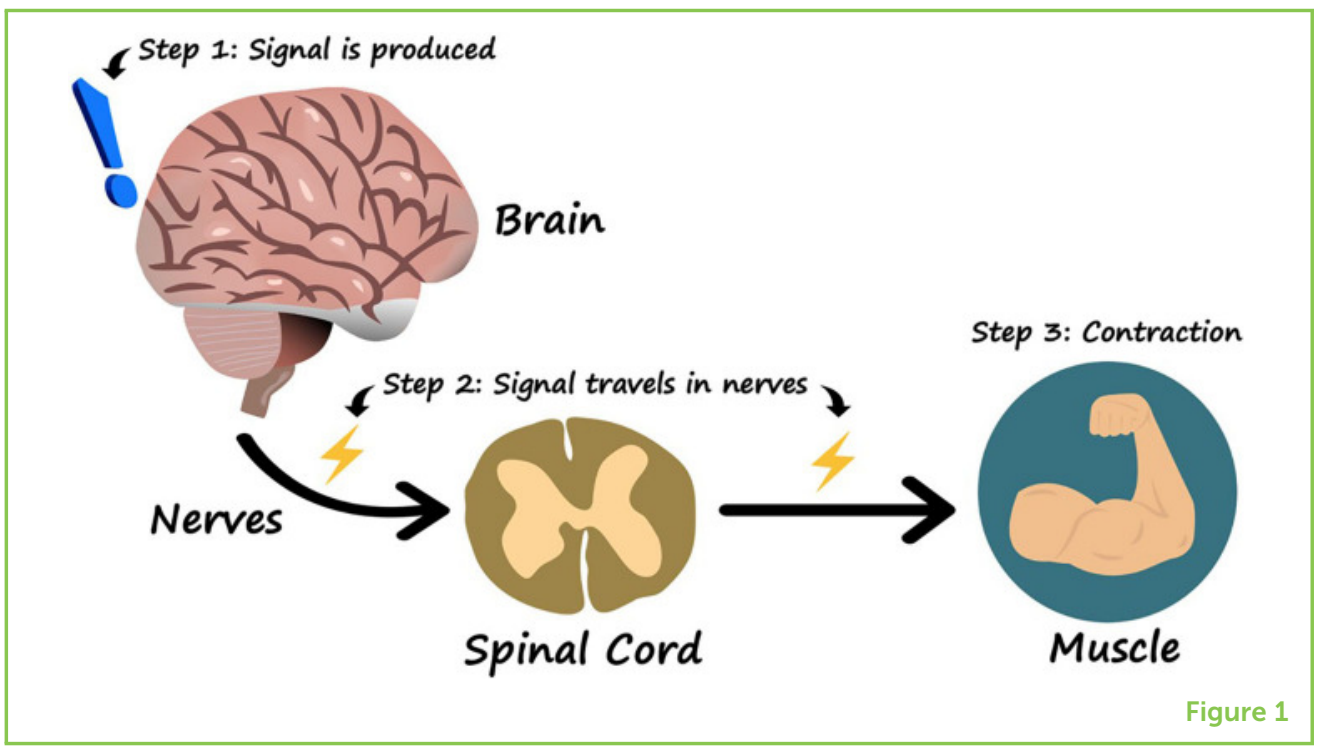

\section{HOW YOUR BRAIN CONTROLS YOUR MUSCLES}

Have you ever felt super tired after a long gym class? After doing a lot of physical activity, you might have felt like your muscles were weaker than usual. While you may think it is your muscles that are tired, what if it is actually your brain?

Movement requires the contraction of muscles, which requires your brain to communicate with those muscles. This is done in the form of an electrical signal that is carried from the brain to the muscle by a special type of cell called a neuron. Neurons do many things, but one very important role is telling your muscles what to do. Neurons do this using a very long branch called an axon that lets the neurons reach across large distances. However, neurons do not go directly from the brain to the muscles. Rather, they carry signals from the brain through the spinal cord (a collection of neurons that exists in our spines) and then to the muscles (Figure 1). When a muscle receives this signal, it becomes active and contracts.

But what signal does the brain use? And how does the muscle know how much to move? When you decide to move a muscle, a positively charged chemical called sodium moves into neurons. The movement of these positive charges into the neuron causes tiny "gates" all along the length of the axon to open, allowing even more positively charged sodium to enter the neuron. As new gates open in response to sodium, the gates behind them that had opened earlier close. Thus, the positive electrical-chemical charge travels all along the length of the axon, through the action of opening and closing gates. When this electrical-chemical charge arrives near the muscle, a chemical signal is released from the neuron that causes the muscle to contract or move. How strongly the muscle contracts depends on how many signals arrive and how quickly they arrive. If you are picking up a feather, the 
PERIPHERAL

\section{FATIGUE}

Fatigue that originates from our muscles.

PERIPHERAL NERVE STIMULATION (PNS)

Stimulation of a nerve using electrodes attached to the skin that deliver fast pulses of electricity. brain would only send a few signals because you do not need a lot of strength to move something so light. But if you are picking up a brick, more signals would be sent more quickly because the brick is heavier and requires more effort!

This brings us back to the main question: If you have been running for a long time, your legs may be feeling tired, but how do we know what is causing that fatigue? Maybe it is not actually your muscles that are tired; maybe your brain is not sending signals to your leg muscles quickly enough anymore, or something in your spinal cord is slowing down the signals. Even though your leg muscles could move more, if your brain and nerves are not effectively able to tell them to move, they would not. So how can we tell whether the problem is the muscles or the brain?

\section{ARE YOUR MUSCLES TIRED?}

Peripheral fatigue is the word we use to describe changes in the muscle itself or at the junction between the neurons and the muscle. In peripheral fatigue, the muscle is truly unable to generate the same amount of force as it used to. You may have noticed this feeling while doing push ups, which get harder and harder the more of them you do.

There are many factors that can cause muscles to get fatigued. One is that the muscles may react less to signals sent from the brain during exercise. For muscles to respond to signals from the brain, the amount of electric charge within the muscle cell must change. Specifically, the inside of the muscle cell must become more positive. Once the inside of the muscle cell is positive enough, this cell can react to signals from the brain. However, during maximal exercise, positive charges may escape from muscle cells [1]. This leaves the inside of the muscle cells more negative and less responsive to the signals sent along neurons. You may be wondering how long this kind of peripheral fatigue will last, and when you will be back to your usual strength. As you have probably guessed from your own experiences, fatigue is not permanent. If athletes got weaker after every exercise, then they would not train anymore! In truth, exercising and short-term fatigue make you stronger with time. Depending on the intensity of exercise, it may take minutes, hours, or even days to recover from peripheral fatigue [2].

\section{ARE YOU EXPERIENCING PERIPHERAL FATIGUE?}

To determine if you are experiencing peripheral fatigue, you will have to go to an exercise lab for testing using a technique called peripheral nerve stimulation (PNS) [3]. PNS uses small devices called electrodes that attach to the skin like stickers and send small, fast 
Figure 2

Measuring peripheral fatigue using PNS. Two electrodes (one positive and one negative) are applied to the muscle using specialized stickers. Stimulating the electrodes causes the muscle to contract as a muscle twitch. The muscle twitch is recorded using a force-transducer (green, connecting the handgrip to the computer), which measures the strength of the muscle contraction. We can check for peripheral fatigue by comparing whether the recorded twitch measured by the force-transducer is smaller after exercise (indicating peripheral fatigue) or remains the same (indicating no peripheral fatigue).

\section{CENTRAL FATIGUE}

Fatigue that originates from our brain and central nervous system.

CENTRAL NERVOUS SYSTEM (CNS)

The brain and spinal cord.

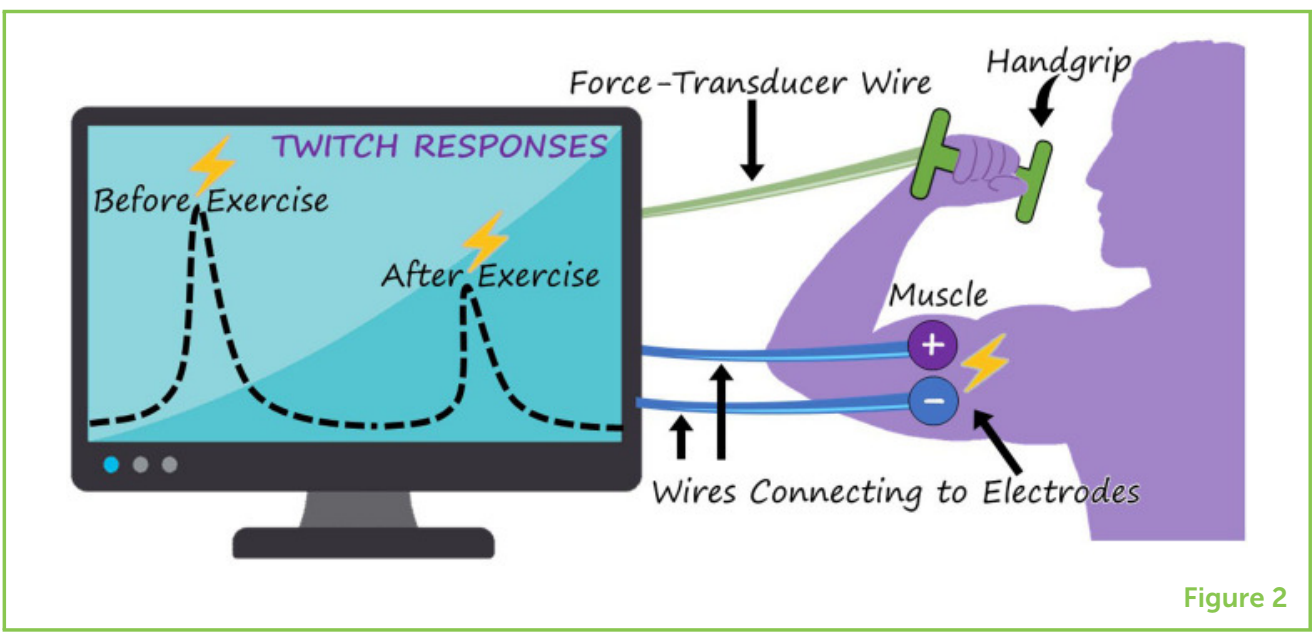

pulses of electricity that feel like gentle tingles into your body [2]. The response of your muscle to this stimulation can then be measured using a special device that measures the force of the resulting muscle movement [2].

Once electrodes are on your skin and you are comfortably resting, scientists will stimulate the nerve using the electrodes. This stimulation causes your relaxed muscle to briefly and strongly contract, resulting in what is known as a muscle twitch. Your muscle twitch will be measured before and after some type of muscle-tiring exercise. This may be knee extensions, in which you bend and extend your leg from the knee, like kicking a soccer ball, or may be an exercise that uses your arm. It all depends on which muscle the scientists want to study! If the twitch produced after exercise is smaller than the twitch produced before exercise, this means your muscle lost some ability to contract (Figure 2). Voila! This is peripheral fatigue.

\section{BRAIN OVER MUSCLE}

When you are asked to help carry many bags of groceries from the car, you may notice that the bags feel heavier and heavier the more trips you do. While your muscles could be guilty of peripheral fatigue, the culprit might be something else. Central fatigue is a type of fatigue that originates inside your brain [4]. In this case, regardless of whether your muscles are tired or not, your central nervous system (CNS) - the brain and spinal cord-is not able to effectively send strong enough signals to drive your muscles to put in the most effort possible.

In many ways, the CNS acts like a computer, producing electrical signals using special chemicals that send messages through neurons. Your neurons are like wires that carry this information all around your body and can cause an action when the signal reaches the muscles. Your muscles need a signal that is powerful enough to make them contract. If there is a change in the ability of your CNS to signal 
Figure 3

Measuring central

fatigue using the twitch interpolation

technique. Central

muscle fatigue is tested by sending a stimulus

through electrodes into

the muscle during a

Maximum Voluntary

Contraction (i.e.

MVC)-when the

muscle is contracting

as much as possible. If

the strength of the

twitch during the

stimulus is higher than

the normal MVC

strength, then the

muscle is still able to

work harder, meaning

that there is central

fatigue. If there is

minimal or no change

in the MVC in response

to the stimulus, then

fatigue is likely

peripheral.

MAXIMAL

VOLUNTARY

CONTRACTION

(MVC)

The greatest amount of strength you can create by deciding to contract either a single muscle or group of muscles.

\section{TWITCH}

\section{INTERPOLATION}

\section{TECHNIQUE}

While contracting your muscle as much as possible, an electrode is used to deliver a pulse of electricity to see if your muscle can contract even more, resulting in a twitch.

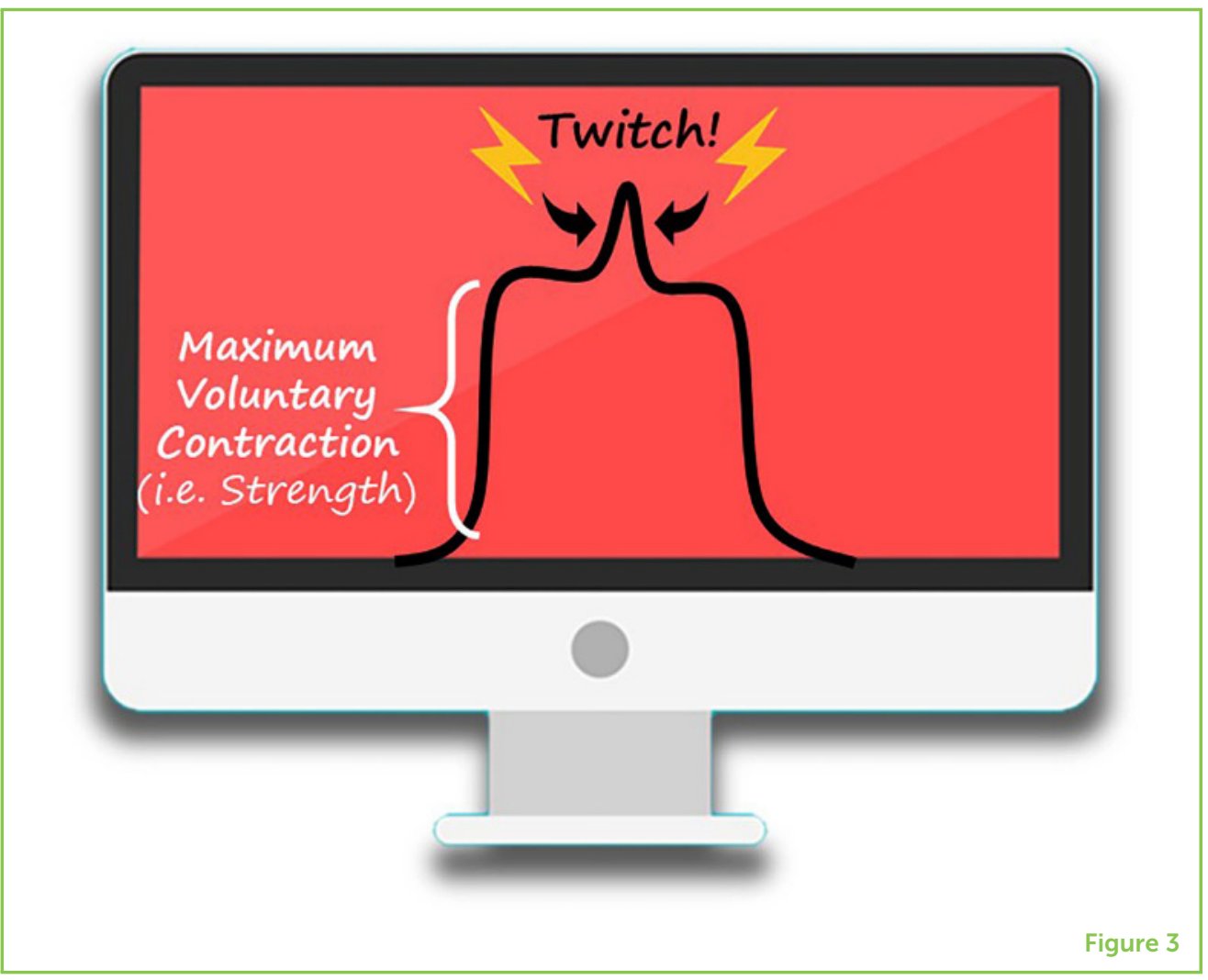

to your muscles, then your muscles will not be able to contract at their strongest, even when you think you are using them to their maximum. This can be measured by asking someone to perform what is known as a maximal voluntary contraction (MVC). The MVC is the maximum force you can generate with your muscle by trying. Central fatigue usually occurs when you are exhausted from exercising for long periods, like carrying heavy groceries. Central fatigue may be a way to protect your muscles from injury that could occur if you overuse the muscle. When you experience central fatigue, it takes at least a few minutes for your brain to recover and be able to send signals at full power again [2]. However, certain exercises may need days for recovery [2].

\section{MEASURING HOW TIRED YOUR BRAIN IS}

If central fatigue all happens in the CNS, how do we measure it when we cannot directly see it or touch it? One scientist discovered that central fatigue could also be measured with electricity, using a technique known as the twitch interpolation technique $[5,6]$. While peripheral fatigue is assessed by measuring the muscle twitch that occurs when a resting muscle is stimulated, central fatigue is measured by assessing the muscle twitch in response to stimulation while you are voluntarily generating an MVC, like squeezing your fist really hard or maximally kicking your leg. If stimulating your muscles with an electrical impulse can generate more strength than your MVC alone, 
it means your muscles were not actually contracting as much as they were able, even though you were trying your hardest (Figure 3 ). This is a classic sign of central fatigue! The missing strength was a result of your brain not sending strong enough signals!

\section{CONCLUSION}

In conclusion, the tiredness you feel after hard physical work can occur in different ways. Although you might think it is just your muscles that are tired, your brain can play a very major role too. Being able to tell whether someone is limited in their physical activities because of peripheral fatigue or central fatigue becomes even more important when looking at what is stopping athletes from reaching their next major performance milestones, or when trying to help people with chronic health conditions more effectively perform daily activities of living, like going up a set of stairs, cleaning, or dressing themselves. The next time you get tired, consider whether it might be from peripheral or central fatigue, or even both!

\section{ACKNOWLEDGMENTS}

Figures in this review were created using a combination of PowerPoint and images publicly available through Creative Commons.

\section{REFERENCES}

1. Juel, C. 1986. Potassium and sodium shifts during in vitro isometric muscle contraction, and the time course of the ion-gradient recovery. Pflügers Archiv. 406:458-63. doi: 10.1007/bf00583367

2. Carroll, T. J., Taylor, J. L., and Gandevia, S. C. 2017. Recovery of central and peripheral neuromuscular fatigue after exercise. J. Appl. Physiol. 122:1068-76. doi: 10.1152/japplphysiol.00775.2016

3. Mortimer, J. T., and Bhadra, N. 2004. "Peripheral nerve and muscle stimulation," in Neuroprosthetics, eds K. W. Horch and G. S. Dhillon (Singapore: World Scientific Publishing Co. Pte. Ltd). p. 638-82. doi: 10.1142/978981mor2561763 $-0020$

4. Zory, R., Boerio, D., Jubeau, M., and Maffiuletti, N. A. 2005. Central and peripheral fatigue of the knee extensor muscles induced by electromyostimulation. Int. J. Sports Med. 26:847-53. doi: 10.1055/s-2005-837459

5. Herbert, R. D., and Gandevia, S. C. 1999. Twitch interpolation in human muscles: Mechanisms and implications for measurement of voluntary activation. $\mathrm{J}$. Neurophysiol. 82:2271-83. doi: 10.1152/jn.1999.82.5.2271

6. Merton, P. A. 1954. Voluntary strength and fatigue. J. Physiol. 123:553-64. doi: 10.1113/jphysiol.1954.sp005070

SUBMITTED: 30 June 2020; ACCEPTED: 16 February 2021; PUBLISHED ONLINE: 12 March 2021. 
EDITED BY: Ajithkumar Vasanthakumar, Peter Doherty Institute for Infection and Immunity, Australia

CITATION: Zhang D, Li J, Miller R, Batraka M, Effing SMA, Hossain F, Bernard A-C, Marillier M and Domnik NJ (2021) Are Your Muscles or Your Brain Making You Feel Tired After Exercise? Front. Young Minds 9:578431. doi: 10.3389/frym.2021.578431

CONFLICT OF INTEREST: The authors declare that the research was conducted in the absence of any commercial or financial relationships that could be construed as a potential conflict of interest.

COPYRIGHT (c) 2021 Zhang, Li, Miller, Batraka, Effing, Hossain, Bernard, Marillier and Domnik. This is an open-access article distributed under the terms of the Creative Commons Attribution License (CC BY). The use, distribution or reproduction in other forums is permitted, provided the original author(s) and the copyright owner(s) are credited and that the original publication in this journal is cited, in accordance with accepted academic practice. No use, distribution or reproduction is permitted which does not comply with these terms.

\section{YOUNG REVIEWER}

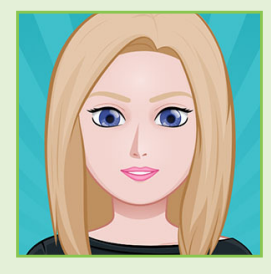

\section{MORGAN, AGE: 13}

Hi, my name is Morgan and I am 13. I like to read books (my favorites are still the Harry Potter series). I also like to go indoor climbing and play soccer. My favorite TV show is Friends and my favorite animal is a kangaroo. I have three bunnies that are adorable.
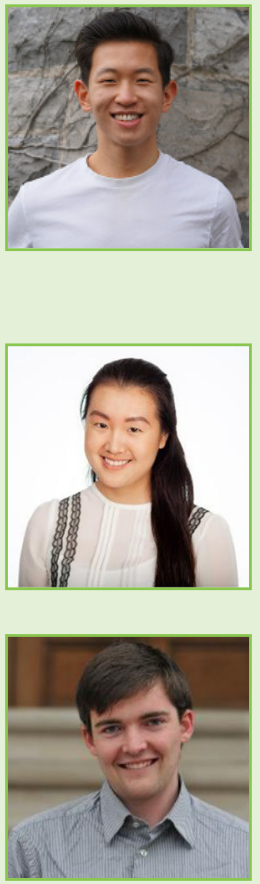

\section{AUTHORS}

\section{DEREK ZHANG}

Derek Zhang is an undergraduate Life Sciences Specialization student at Queen's University. His academic interests focus on biomedical research and pathologies, as well as clinical sciences. His passion for helping children has led him to aspire to enter medical school and become a pediatrician! He likes to cook and work out in his spare time.

\section{JUANA LI}

Juana Li is an undergraduate student at Queen's University, majoring in Life Sciences. She is also interested in classical studies. Her research interests are in medical education and bibliometrics. She hopes to someday become a clinician-educator. In her free time, she likes to read historical fiction, bake, and play basketball.

\section{RYAN MILLER}

Ryan Miller is a Life Sciences major at Queen's University. His current research focuses on preventative mental health strategies, although his interests vary widely and include subjects, such as mathematics and history. His current goal is to be accepted to medical school. In his leisure time he likes to play chess, video games, and various sports. 

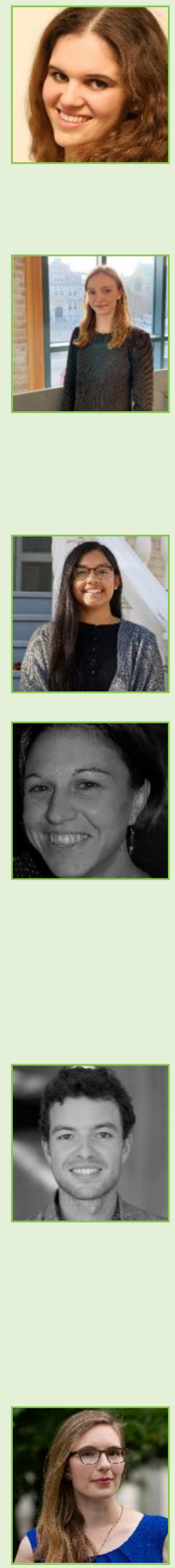

\section{MARINA BATRAKA}

Marina Batraka is an undergraduate Life Sciences student at Queen's University. She is interested in medicine and how the human body works. She loves teaching and sharing her knowledge to help people understand why their bodies do certain things. She wants to be a pediatrician working on keeping children and youth healthy and happy. Outside of her interests in medicine, she loves cooking, dancing, and going on hikes or walks with her dog.

\section{SOPHIE MARIE ANNE EFFING}

As an undergraduate student studying Life Sciences at Queen's University, Sophie Effing is learning about health and the human body. By pursuing a Certificate in Business, she is also gaining a better understanding of various ways the world works. Her passion for healthcare has led her to pursue a path in global and population health that will hopefully allow her to have a positive impact on the world. Apart from studying, she enjoys staying active by playing soccer and working out, spending time with friends and family, and learning to play chess!

\section{FAHMIDA HOSSAIN}

Fahmida Hossain is an undergraduate student at Queen's University studying Life Sciences. Her dream is to pursue a medical career in Trauma and Orthopedic Surgery. When she is not studying, she is most likely singing in her a cappella group, tutoring students, or playing her guitar!

\section{ANNE-CATHERINE BERNARD}

Anne-Catherine Bernard is a clinician who earned her M.D. from Grenoble Alpes University (France) with a specialization in sports medicine. She recently completed a 2-year research fellowship in the Department of Medicine at Queen's University (Kingston, Canada), where she investigated how the lack of oxygen during exercise affects neuromuscular fatigue in patients with interstitial lung disease. Dr. Bernard is interested in exploring new ways of customizing physical activity to make it accessible to everyone, including helping amputees and people with chronic respiratory diseases or obesity find types of physical activity that work well for them.

\section{MATHIEU MARILLIER}

Mathieu Marillier is a clinical exercise physiologist. He earned his Ph.D. from Grenoble Alpes University (France) where his research focused on the consequences of sleep disorders on the brain during subsequent exercise. He recently finished a post-doctoral fellowship in the Department of Medicine at Queen's University (Kingston, Canada), where his research involved exercise intolerance in chronic respiratory diseases. Dr. Marillier is currently working as a researcher and is particularly interested in investigating the consequences of not getting enough oxygen on neuromuscular fatigue during exercise, in patients with chronic respiratory disorders.

\section{NICOLLE J. DOMNIK}

Nicolle Domnik has taught physiology and pathophysiology at Queen's University for 6 years and is a recently-appointed assistant professor at Western University. She loves sharing her passion for physiology with her students by helping translate research into real life. Her research has investigated the impact of chronic 
respiratory disease on the ability to breathe during sleep as well as how specialized neurons in our lungs sense our breathing movements and what is in the air. When she is not thinking about lungs, she can usually be found experimenting in the kitchen, making music, enjoying the great outdoors, or seeking scientific advice from her most discerning reviewer: her cat. *n.j.domnik@queensu.ca; nicolle.domnik@schulich.uwo.ca 